\title{
Animation Production Teaching Model based on Design-Oriented Learning
}

\author{
https://doi.org/10.3991/ijet.v13i08.9049 \\ Ben Ma \\ University of Science and Technology Liaoning, Ansha, China \\ zhang-lu2009@163.com
}

\begin{abstract}
The course of two-dimensional animation production focuses on practice. In teaching, more attention should be paid to cultivation of students' innovation ability, team cooperation ability and similar prior education goals. With the promotion of paperless animation design courses, the animation production process should include the knowledge points in teaching. With this regard, taking the advantages of Flash software, an animation teaching model based on design-oriented learning was constructed in this study relying on design-oriented learning theory in animation production teaching, and taking project-oriented learning and empirical learning theory as guidelines. Meanwhile, comparison was made with the traditional teaching methods that only emphasize the presentation and transmission of knowledge. The research results show that using Flash software with design-oriented animation production teaching model makes it easier for students to accept knowledge when compared with the traditional PPT teaching model. It cannot only fully mobilize the learners' enthusiasm, initiative and independent innovation, but also promote the students' ability to study independently and constantly throughout their life. The Flash teaching platform adopted in the teaching process facilitates teacherstudent interaction, team communication, and resource sharing, and is an effective assistant in the multimedia teaching process.
\end{abstract}

Keywords-Multimedia teaching; Animation Production; Design-oriented Learning; PPT teaching

\section{Introduction}

In modern education, people have paid increasing attention to the cultivation of higher-order thinking and advanced abilities by using design-oriented learning theory. Schools have also followed the pace of this new thinking and accelerated the theoretical research and practical application of design-oriented learning theory in their teaching. The application of the teaching model based on design-oriented learning, as some researchers pointed out, not only enables learners to accumulate knowledge but also benefits the cultivation of the higher-order thinking and innovation abilities of students [1]. As its unique value, design-oriented learning improves the teamwork, cooperation, and innovation ability of learners when analyzing and solving problems. 
Therefore, promoting and applying design-oriented learning can introduce substantial changes to the current education and teaching reforms. Unlike traditional teaching methods that only emphasize the display and transmission of knowledge, designoriented learning adopts a new learning model and teaching idea and has broad application prospects in computer education courses [2].

\section{State of the art}

The people's demand for animation design has increased along with the continuous development of computer network and multimedia technologies. Various educational institutions have also begun to offer a course on 2D animation production. However, the strong practicality of this course requires students to not only master the basic theoretical knowledge of animation production but also develop abilities in animation design. Nevertheless, one cannot effectively teach animation design by simply relying on traditional verification operation experiments or examinations [3]. Students also need to exercise appropriate design and innovation abilities in practice under the guidance of effective teaching theories. Design-oriented learning is a new learning method that has emerged in the education field in foreign countries that aims to cultivate the innovation ability of students in designing experimental products $[2,4]$.

The teaching of design courses in China greatly relies on the traditional teaching model, where the teacher plays the role of the protagonist in the classroom while the students passively accept the knowledge that they receive from their teachers. The teaching process generally follows this procedure: explanation of the relevant basic theoretical knowledge, explanation of the examples, demonstration by the teacher, and molding case operation or study. As its display method, this model employs a presentation of words or a summarized PPT presentation. This model is undoubtedly monotonous and boring, easily leads to learning fatigue, and fails to motivate students to engage in initiative creation. Moreover, these students cannot adapt to various situations after learning a few simple examples in the animation production course. Despite learning a few simple cases, these students still have no idea how they can address the problems that emerge after facing slight changes in design because the traditional teaching model is not applicable to innovative courses, such as animation design.

Foreign teaching models in animation, art, and design courses are more open compared with the traditional teaching model adopted in China, and many countries have incorporated the concept of design-oriented learning into their reform of teaching models. For instance, the "Maker Education Program" in the US [5] and the "National Science and Engineering Contest" in the UK [6] aim to promote the design-oriented learning model in order to enhance the innovation ability of students. Atman [7] used several quantitative and qualitative methods to examine engineering design learning and found that those students who take a course in engineering design and/or are studying engineering for four years have acquired engineering design language that is commonly practiced in large communities and in their respective programs and higher learning institutions. Atman also suggested that engineering design language shapes 
the knowledge of students about engineering design. In teaching computer courses, Domínguez et al. [8] applied design-oriented learning that integrated project-based learning as well as project management techniques and tools. This approach also provides some scaffolding at the beginning, adapts to different student-proposed domain projects, and emulates actual operations in database design. They found in their experiment that design-oriented teaching achieves better teaching effects compared with the traditional teaching model. Notably, the 3D computer animation course is known for its high level of professionalism and operability. Based on design-oriented learning, Zheng et al. [9] proposed the teaching activity model with "course preparation $\rightarrow$ selection by the student $\rightarrow$ design learning" as its main principle and learning evaluation as its main monitoring means. The rational use of design-oriented learning can effectively solve some problems in programming teaching, such as the low interest in learning, poor programming skills, and weak practical applications. In short, animation production teaching emphasizes the enthusiasm, initiative, and innovation ability of students, but the current animation teaching model in China does not promote the interest, animation production, and employability of students. The goal of the design-oriented learning model proposed in this study is to help students learn design. According to this model, students need to actively collaborate and finish design tasks that require multidisciplinary practical application. The goal of designoriented learning satisfies the teaching requirement of animation production experiments, that is, paying attention to the "discussion of practical problems and teamwork design." Therefore, the design-oriented learning model can fundamentally solve the problem being faced by the traditional Chinese teaching model in animation design teaching, namely, the inconsistency among learning, research, and creation. This study examines the application of design-oriented learning theory in the animation production course to check the feasibility of applying such theory in teaching animation production.

\section{Animation Production Teaching Model That Integrates Design-Oriented Learning}

Design-oriented learning must be based on the development of the project to improve the acquisition of knowledge and the ability of students to complete such project. Design-oriented learning incorporates inquiry activities and design practices. This process usually begins with a design-oriented learning challenge proposed by the teacher. Afterward, the learners work together in a series of activities, including repeated exploration, design, iteration of design results, and design of the finished product, to complete this challenge. In teaching practice, a specific design-oriented learning model can be combined with the characteristics of each course.

With the development of paperless animation technology, animation production teaching has begun to explore paperless animation teaching models. However, this exploration requires teachers to go beyond the traditional theory-oriented teaching, describe the teaching model, and integrate the knowledge points of the course into the animation production process. One of the most effective strategies for exploring pa- 
perless animation teaching models is using the appropriate computer software to produce animations. The Adobe Flash Player software is known for its many advantages, including its simple operation, small file size, comprehensive functions, and applicability as a teaching software for animation design courses.

The construction and application of a Flash animation production teaching model based on design-oriented learning were explored in this study by combining this model with the characteristics of design-oriented learning, by using the Adobe Flash Player software, and by learning from the project-based and experimental learning models.

\subsection{Project-based learning}

Project-based learning requires students to explore practical issues in depth and design products at the same time. Students can acquire the necessary knowledge and skills by solving complex realistic issues. The PBL teacher manual clearly states that the tasks in project-based learning must be complex enough to create challenges for the students. These challenges can be completed through design, problem solving, teamwork, investigation and exploration, and decision making. The number of extracurricular activities must also be increased in the learning content that focuses on classroom teaching. Enlightenment must be prioritized in the teaching process, and the organization of activities must consider the integration of various resources, methods, and ways with an open mind. Establishing learning groups presents a favorable strategy for strengthening the cooperation among team members. In projectbased learning, the learning project is real, the learning evaluation is problemoriented, the project is student based and teacher assisted, and teamwork and comprehensive use of various knowledge are highlighted [9].

\subsection{Experimental learning}

Kolb proposed a four-phase model of experimental learning that includes concrete experience, reflective observation, conceptualization, and active experimentation. According to this theory, experimental learning must allow students to experience and learn in actual situations. When faced with new problems, these students can use the constructed theoretical model to solve related problems and to verify the rationality and reliability of their design ideas. In other words, experimental learning is based on experience. In the learning process, students can openly interact with their teams or the outside world. In this way, their experience and knowledge are constantly enriched, updated, tested, and iterated while solving problems, thereby bringing them new knowledge, experience, and capabilities.

\subsection{Construction of the design-oriented learning model of animation production}

According to the above theory, this study was based on creator education to enhance the learning and innovation abilities of students. From the perspective of teacher-student cooperation, a design-oriented learning model of animation production was constructed by using the Adobe Flash Player software as shown in Figure 1. 


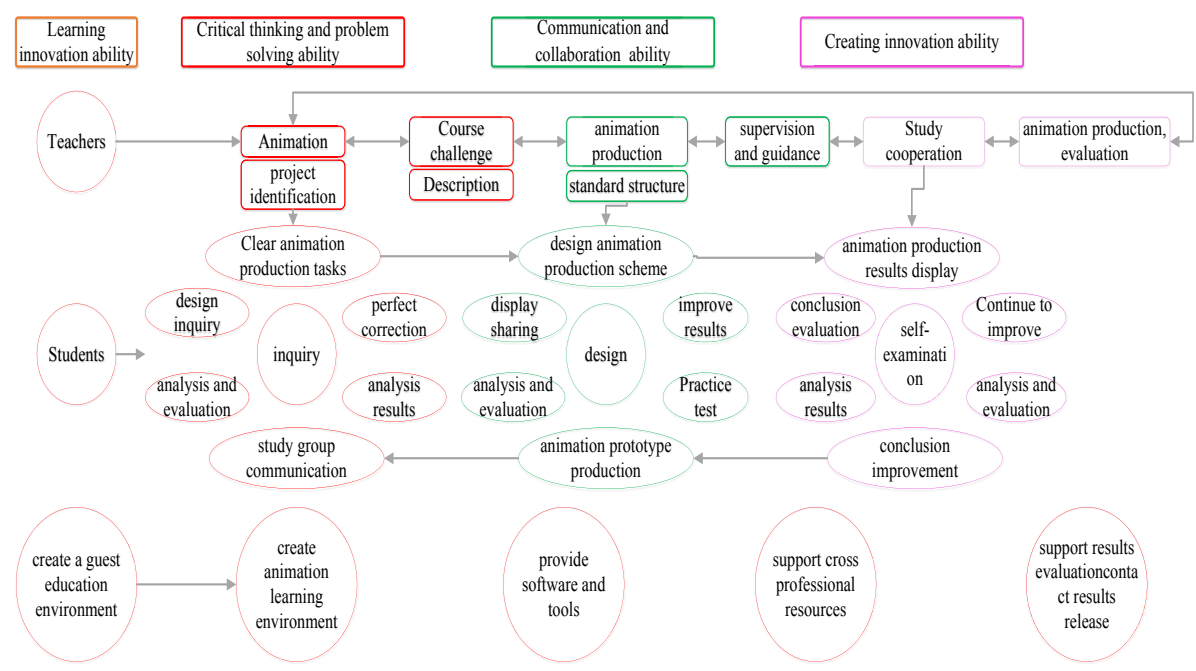

Fig. 1. Diagram of the design-oriented learning model of Flash animation production

\section{Teaching Implementation and Teaching Effect}

\subsection{Teaching Implementation}

In line with the model diagram established above, the teacher proposes the task, "production of sports Flash animation for primary school students." As shown in Figure 2, the learning process was divided into three phases and seven links.

This procedure ensures that the students explore animation production by relying on Flash technology during the learning and design processes. The Flash teaching platform system was also adopted to make various arrangements for the course. The Flash animation teaching platform includes several modules of the teaching process that correspond to the implementation of relevant links in the teaching process as shown in Figure 3.

Each module can track all links in the implementation process of animation production teaching, thereby effectively controlling the entire teaching schedule, controlling the implementation details, and facilitating the communication and information exchange between the students and their teachers and among team members. The process analysis in Figure 4 was used to study the outcomes of animation production.

The design-oriented teaching model was used for the Flash production of "Grass bends as wind blows." 


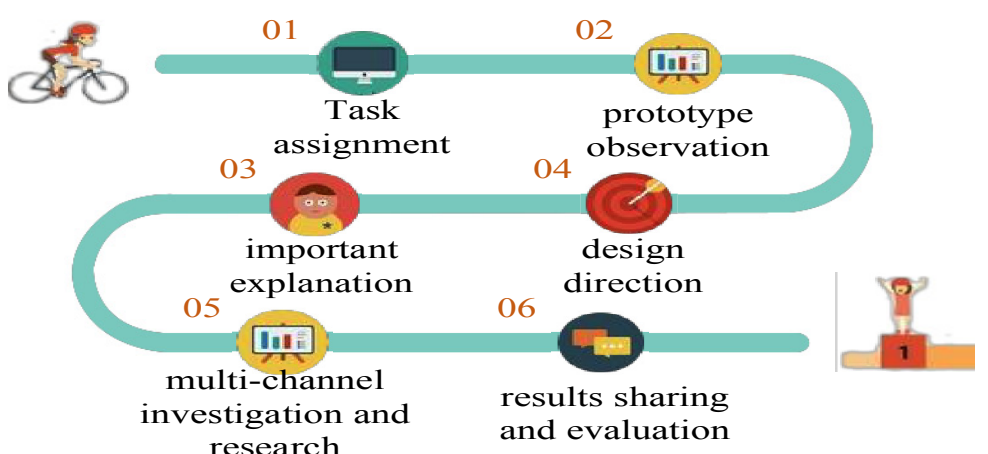

Fig. 2. Steps in implementing the animation production design-oriented learning course based on the Adobe Flash Player software

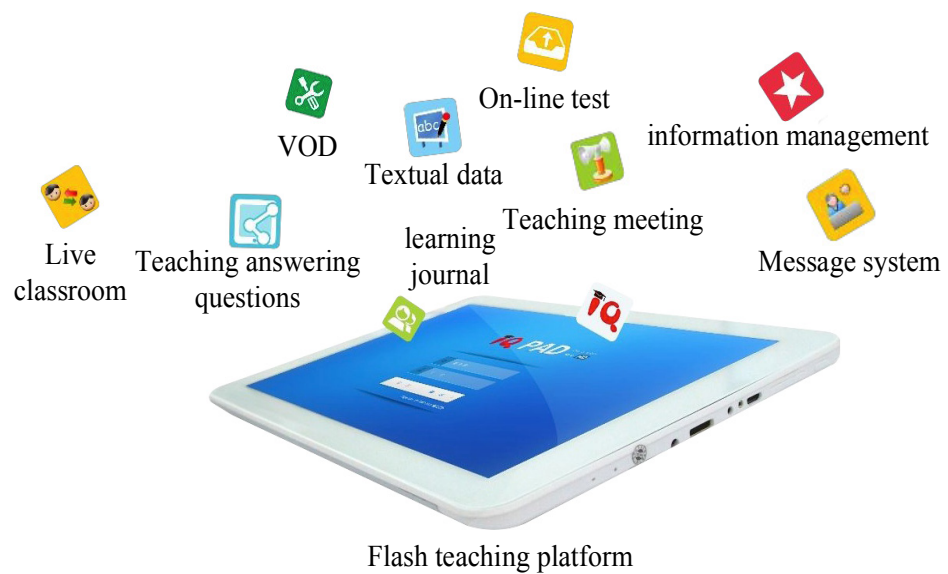

Fig. 3. Modules of the teaching process tracked by the Flash teaching implementation platform

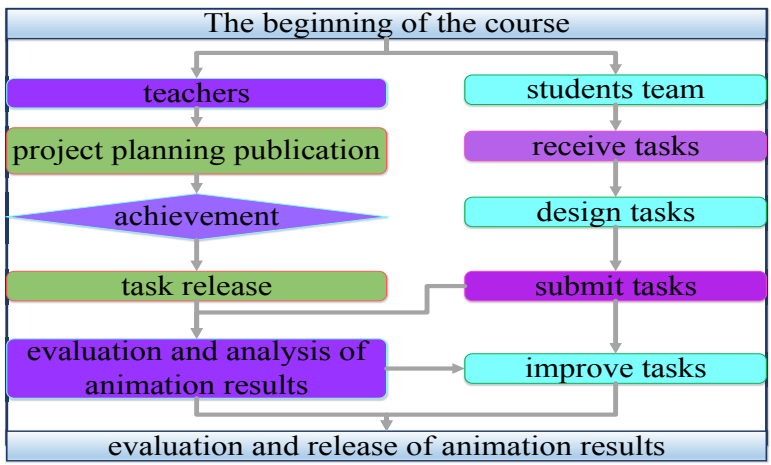

Fig. 4. Process of feedback, iteration and evaluation of results 
First, "Grass 1" was dragged to the main scene, and few similar grass blades were drawn and arranged. Some flowers could also be drawn for embellishment. As shown in Figure 5, a pencil tool was used to draw the approximate shape of grass, followed by "coloring" in Figure 6. Shape animation was then performed as shown in Figure 7. The wire frame was erased followed by shape animation. A key needle was inserted in the 10th needle. The shape and position of the grass blades were then adjusted followed by shape twining. Afterward, the key needle was inserted in the 20th needle. The grass blades returned to their original shape in the first needle, and all prior actions were placed in an MC. Several different shapes of grass blades were drawn in a similar manner. A new MC "Grass 1" was used to copy the grass, build layers, and arrange them to form a set of grass shapes.

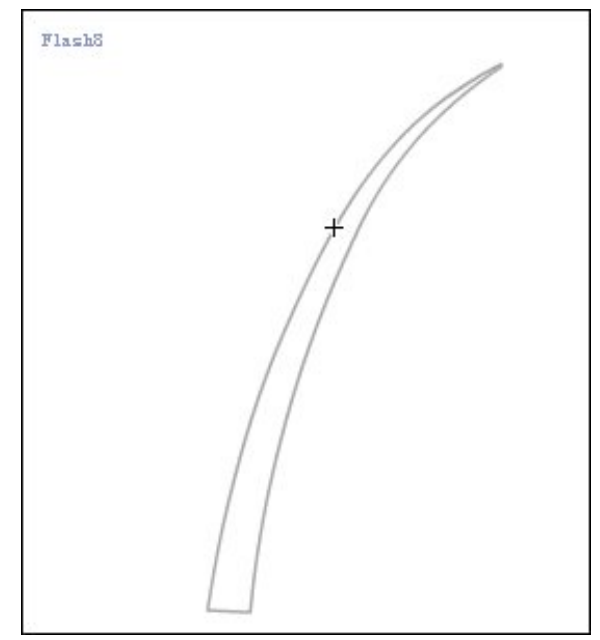

Fig. 5. Function design process of SOPC-based "Format Factory" conversion system

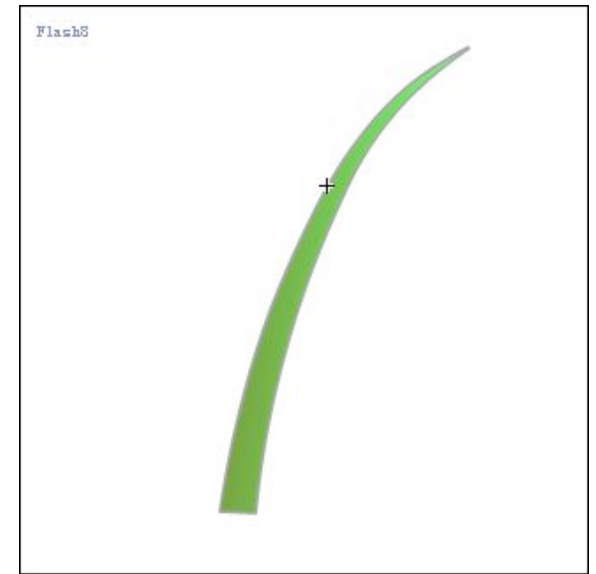

Fig. 6. Procedure II of using the design-oriented teaching model for the FLASH production of "Grass bends as wind blows" 


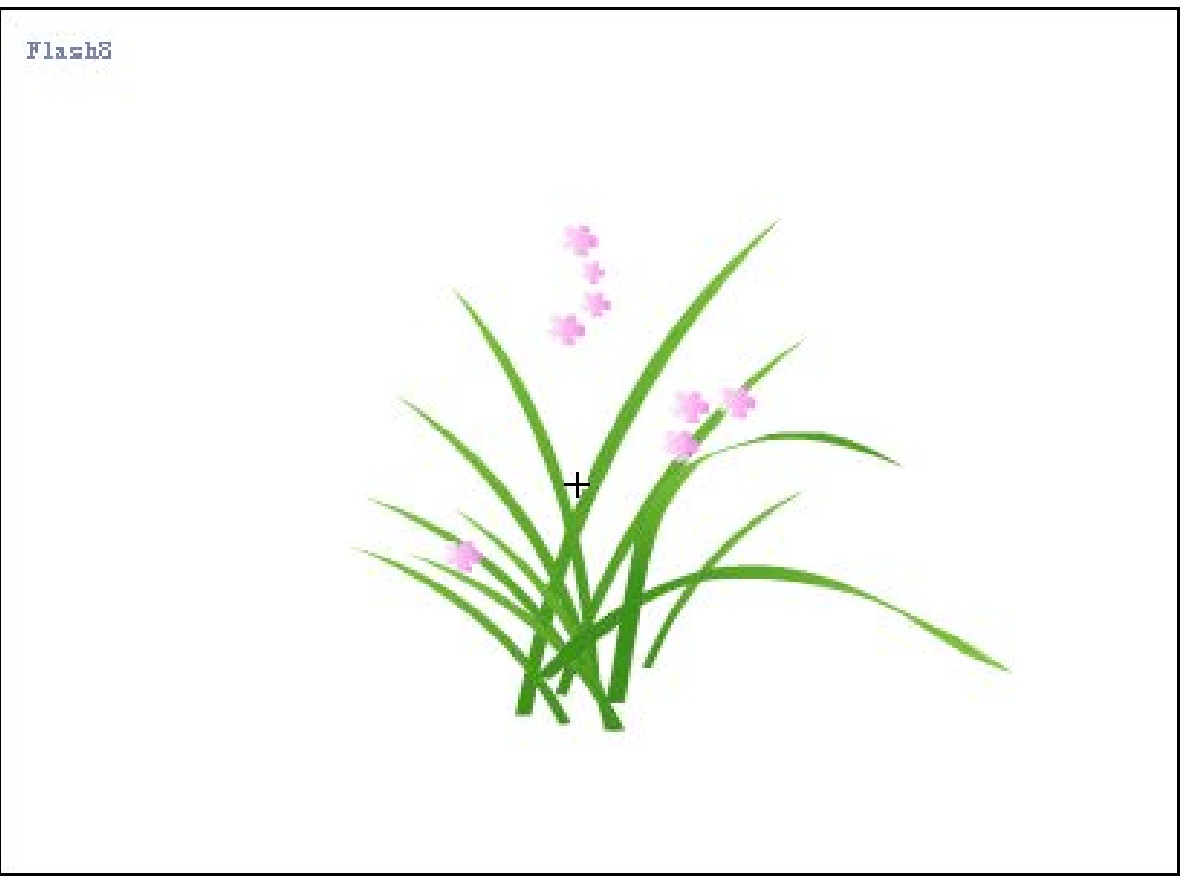

Fig. 7. Procedure III of using the design-oriented teaching model for the FLASH production of "Grass bends as wind blows"

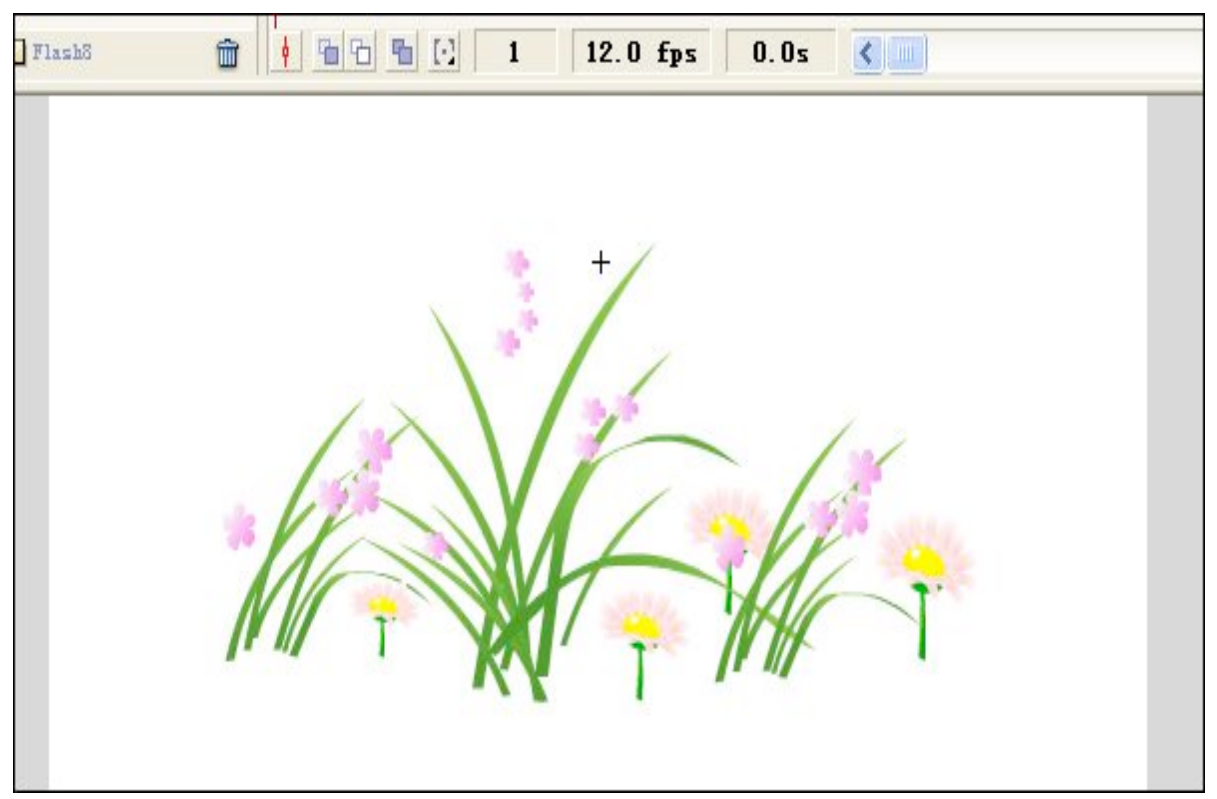

Fig. 8. Procedure IV of using the design-oriented teaching model for the FLASH production of "Grass bends as wind blows" 


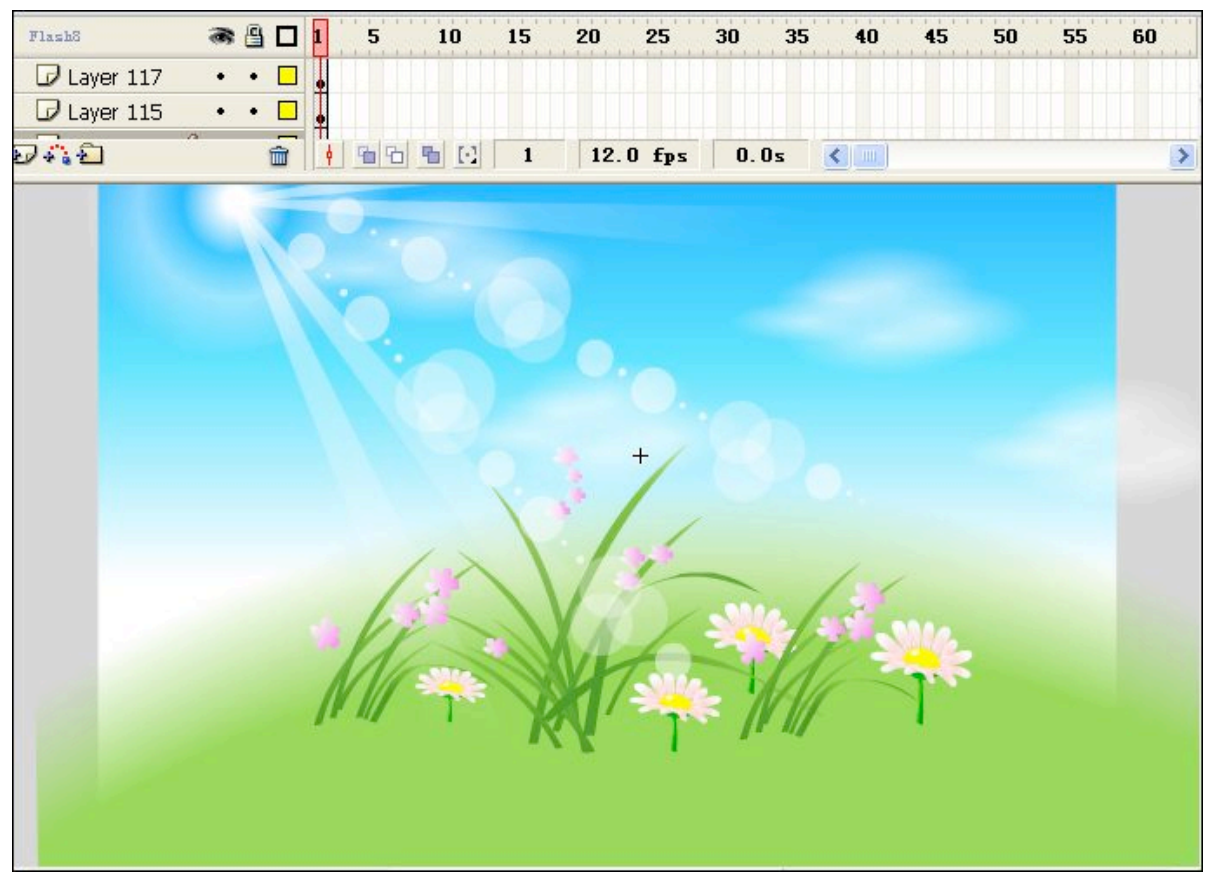

Fig. 9. Procedure V of using the design-oriented teaching model for the FLASH production of "Grass bends as wind blows"

\subsection{Teaching effect}

To evaluate the implementation effect of the Flash animation production teaching model based on design-oriented learning, the traditional PPT teaching method and the design-oriented teaching model established in this study were used to convey the same knowledge to two peer classes of students. After teaching, a questionnaire survey was conducted to determine these students' mastery of the knowledge points. The same evaluation criteria were used to analyze the completed animation works. The 40 students in each class were divided into 8 groups to complete the production of animation works.

The understanding of the students about the knowledge points involved in the animation production process was classified into (1) fully mastered, where the student has a clear understanding of the knowledge points, can give accurate answers, and can draw inferences, (2) mastered, where the student has an accurate understanding of the knowledge points and can accurately answer the relevant questions, (3) basically mastered, where the student can give relatively clear answers to the key knowledge points but provides an imperfect description, and (4) not mastered, where the student does not have a thorough understanding of the knowledge points and gives wrong answers.

The statistical process was performed by using the SPSS 19.0 software. The frequency $P(\%)$ was used as the count data, and $\chi^{2}$ was used as the test index when 
comparing the two groups. Based on the characteristics of the statistical data, the exact probability test method was conducted to compare the count data, and the difference was considered statistically significant when $P<0.05$. The Cronbach's coefficient $\alpha$ was used to test the reliability of the questionnaire, and the total test coefficient $\alpha$ was equal to 0.83 , thereby indicating that the questionnaire has good reliability and universal applicability. The results of the questionnaire survey for the two classes are shown in Table 1.

The animation works produced by the students were anonymously evaluated by five professional teachers of animation production in terms of their meeting of technical requirements, use of animation sound effects, structural integrity, fluency of the pictures, interpretation matching, and similar factors. The 100-point system was adopted for the scoring. The number of students who obtained 85 points or higher in each item was counted. The results of the evaluation are presented in Table 2.

Table 1. Results of the questionnaire survey for the control and experimental classes

\begin{tabular}{|l|c|c|c|}
\hline \multicolumn{1}{|c|}{ Knowledge points } & Control class $(\mathbf{n}=\mathbf{4 0})$ & Experimental class $(\mathbf{n}=\mathbf{4 0})$ & $\boldsymbol{P}$ \\
\hline Fully mastered & $6(15)$ & $10(25)$ & $<0.05$ \\
\hline Mastered & $12(30)$ & $10(25)$ & $<0.05$ \\
\hline Basically mastered & $36(45)$ & $18(45)$ & $<0.05$ \\
\hline Not mastered & $4(10)$ & $2(5)$ & $<0.05$ \\
\hline
\end{tabular}

Table 2. Results of evaluating the animation works produced by the control and experimental classes

\begin{tabular}{|l|c|c|c|}
\hline \multicolumn{1}{|c|}{ Evaluation criteria } & Control class (n=40) & $\begin{array}{c}\text { Experimental class } \\
(\mathbf{n = 4 0 )}\end{array}$ & $\boldsymbol{P}$ \\
\hline Meet technical requirements & $4(50)$ & $8(100)$ & $<0.05$ \\
\hline Use of animation effects & $1(12.5)$ & $6(75)$ & $<0.05$ \\
\hline Structural integrity & $4(50)$ & $8(100)$ & $<0.05$ \\
\hline Fluency of the pictures & $2(25)$ & $8(100)$ & $<0.05$ \\
\hline
\end{tabular}

As can be seen in Table 1, the teaching effect of the proposed teaching model is superior to that of the traditional PPT courseware teaching model. Specifically, the design-oriented learning model is more conducive to the mastery of knowledge points among most students and allows them to fully understand the knowledge points used in the animation production process in practical application cases. Table 2 shows that the animation works created by using the project-based learning model are significantly better than those created by using the traditional PPT teaching model in terms of meeting the technical requirements, using animation effects, and others. The animations produced by the former are smooth, exquisite, and rich in content. One group even added a skipping plot described in Japanese animation comics to the animation production to make the skipping actions clearer and easily understandable, to inspire the primary school students to use it, and to help primary school students understand and accept it.

The use of Flash software to create animation works has unparalleled advantages over 
the use of other software and can give full play to the simple, funny, and powerful features of Flash software in visible development. The use of this software in interactive multimedia courseware has been especially affirmed by many teachers [11]. This study reveals that the Flash software has a powerful multimedia integration function, allows the input of texts, pictures, and videos, and has a small size, thereby helping students create complex, simulated, and interactive sports animations. The construction of the Flash animation production teaching model based on design-oriented learning can also fully mobilize the initiative, participation, and innovative and subjective initiative of students in their learning process. In the collective brainstorming, cooperation, and sharing processes, classroom knowledge is accepted, absorbed, and understood thoroughly by using an easy-to-understand approach. Meanwhile, when making animations, this model can widen the perspectives of the students, enhance their creativity, and promote collective cooperation. Further analysis reveals that the Flash teaching platform used in this study helped teachers grasp and control their teaching schedules and the progress of their projects. At the same time, the real-time information transmission and effect feedback can help teachers meet the needs of their students in all aspects of the project implementation, thereby facilitating the delivery of the course by using the design-oriented learning model.

In conclusion, the animation production teaching model based on design-oriented learning combined with the use of the Flash teaching platform can achieve better results in teaching animation production compared with the traditional PPT teaching method. This teaching model, which is based on design-oriented learning theory, can also realize the integration and sharing of related resources, arouse the interest of students, mobilize their enthusiasm to create independently, and encourage a high degree of student participation in the implementation of project cases. Meanwhile, the mutual assistance and cooperation among team members can facilitate the inculcation of various integrated teaching resources in order for students to fully understand the application of knowledge points they learned in the classroom, to promote their ability in carrying out their own learning, to boost their persistence in learning, to achieve their educational goals (e.g., training students to analyze and solve problems), and to motivate them to engage in teamwork, innovation, and lifelong learning. When using the Flash teaching service platform, one must consider the various links and situation applications of project management design in teaching. Given the different teaching characteristics of each course, educators must adopt a suitable, rich, and convenient teaching service platform. Further improving the required teaching platform for various courses also presents an important issue for the majority of the teachers.

\section{Conclusions}

To improve the ability of students to innovate in the animation production course, an animation production teaching model that relies on the Flash software was constructed in this study based on the design-oriented learning model. The results indicate the following: 
1. The application of Flash software technology in teaching animation production can help students produce complex, simulated, interactive, and intelligent animations. This technology has the powerful function of multimedia integration and allows the input of texts, pictures, videos, and animation modules. The effect of this technology is also superior to that of the traditional PPT teaching method, which emphasizes the presentation and transmission of knowledge.

2. The animation production teaching model based on design-oriented learning is more easily accepted by students compared with the traditional PPT teaching model. This model can fully mobilize the active participation, active cooperation awareness, and independent innovation of learners in solving practical problems, improve their self-learning, teamwork, and lifelong learning abilities, and develop their ability to analyze and solve problems, cooperate with their team members, and actively explore.

3. The animation production teaching model based on design-oriented learning can be combined with the application of the Flash teaching platform to facilitate mutual exchanges between teachers and students as well as to better grasp the project progress, course orientation, and resource sharing. This platform also greatly facilitates the implementation of the design-oriented learning model.

With the continuous development and expansion of various computer software and the improvement of the teaching platform, the application of design-oriented teaching models in various interactive learning courses is expected to grow in popularity in the future.

\section{$6 \quad$ References}

[1] Wonu, N., Arokoyu, A.A. Design-Based Learning Model and Senior Secondary Students' Learning Achievement in Solid Geometry. European Journal of Scientific Research, 2016, vol. 12(34), pp. 272-283.

[2] Laverde, A.C., Rodríguez, H.Y.R. Toward an Instructional Design Model Based on Learning Objects. Educational Technology Research \& Development, 2007, vol. 55(6), pp. 671681. https://doi.org/10.1007/s11423-007-9059-0

[3] Sun, J.Y., Guo, T.Y. Inquiry and Practice of the Reform of 2D Animation Making Course. Journal of Changchun Finance College, 2012, vol. 15(1), pp. 68-71.

[4] TechTrends. Role-Based Design: A Contemporary Perspective for Innovation in Instructional Design. Techtrends Linking Research \& Practice to Improve Learning, 2008, vol. 52(6), pp. 36-43. https://doi.org/10.1007/s11528-008-0215-0

[5] Lee, J., Jang, J. Development of Maker Education Program based on Softeware Coding for the Science Gifted. 2017, vol. 27(3), pp. 331-348.

[6] Li, J.J., Zhai, Y., Du, Y.G., et al. The Deficiencies and Improvement Measures of Local Science and Engineering Colleges in National Discipline Contest. China Modern Educational Equipment, 2016, vol. 21, pp. 43-45.

[7] Atman, C.J., Kilgore, D., Mckenna, A. Characterizing Design Learning: A Mixed-Methods Study of Engineering Designers' Use of Language. Journal of Engineering Education, 2008, vol. 97(3), pp. 309-326. https://doi.org/10.1002/j.2168-9830.2008.tb00981.x 
[8] Domínguez, C., Jaime, A. Database design learning: A project-based approach organized through a course management system. Computers \& Education, 2010, vol. 55(3), pp. 1312-1320. https://doi.org/10.1016/j.compedu.2010.06.001

[9] Zheng, W.D. Teaching Practice of Programming Courses from the Perspective of Design Learning. China Educational Technology, 2011, vol. 12, pp. 98-101.

\section{Author}

Ben MA is a lecturer in the University of Science and Technology Liaoning, Anshan, China (zhang-lu2009@163.com).

Article submitted 21 April 2017. Resubmitted 25 June 2018. Final acceptance 23 July 2018. Final version published as submitted by the author. 